\title{
Manejo das Estenoses Venosas em Acessos para Hemodiálise
}

\author{
Simão C. ${ }^{1}$ \\ ${ }^{1}$ Belo Horizonte - Brasil. \\ E-mail: charlessimaofilho@gmail.com
}

Simão, C. 2013. Manejo das Estenoses Venosas em Acessos para Hemodiálise, p.63. In: Bastos, Francisco Reis. Anais do V Simpósio Internacional de Flebologia [Blucher Medical Proceedings n.1 v.1]. São Paulo: Blucher, 2014

http://dx.doi.org/10.5151/medpro-flebo-SIF_38
As estenoses de troncos venosos centrais, principalmente no território subclávio-jugular-cava superior, são grandes desafios para o cirurgião vascular na obtenção de acessos temporários e definitivos para hemodiálise. A permanência de cateteres tipo duplo-lúmen, é um dos maiores responsáveis por estes eventos, que impossibilitam a utilização de veias à montante do ponto de estenose, comprometendo a confecção de fístulas artério venosas ou a reutilização de cateteres temporários. O uso crescente destes cateteres é um fator agravante e sua maior causa é a demora de encaminhamento aos centros de hemodiálise.

As estenoses são atribuídas ao trauma endotelial crônico, resultante da pequena movimentação dos cateteres contra a parede venosa, resultando em reações flebíticas agravadas pela aderência de fibrina nas bainhas de cateteres e biofilmes.

As alternativas de tratamento ainda não apresentam resultados satisfatórios em longo prazo. Angioplastias são realizadas desde os anos 80 com patência média de 40\% em um ano. A incorporação de "stents" na última década parece apresentar resultados superiores e a recente utilização de "stents" revestidos ainda não apresenta eficácia comprovada superior aos "stents convencionais".

O tratamento cirúrgico aberto apresenta taxas elevadas de patência, porém são procedimentos de grande porte e risco elevado e devem ser criteriosamente avaliados caso a caso.

A realização de fístulas artério-venosas precoces é a melhor forma de prevenção. Os autores apresentam a sua experiência no tratamento destas lesões e revisão da literatura.

Palavaras-chave: estenose venosa, hemodiálise, fistula arterio-venosa.

\section{Bibliografia}

1. MICKLEY, V., Central Vein Obstruction in Vascular Access; Eur J Vasc Surg 32, 439-444 (2006)

2. KUNDU, S., Review of Central Venous Disease in Hemodyalisis Patients; J Vasc Interv Radiol 2010; 21-963-968 
3. LUMSDEN, A. B.., MACDONALD, M. J., ISIKLAR, H., MARTIN, L. G., KIKERI, D., HARKER, L. A., ALLEN, R. C., Central venous stenosis in the hemodialysis patient: incidence and efficacy of endovascular treatment; Cardiovascular Surgery, vol 5; No 5, pp 504-509, 1997.

4. JAKIMOWICZ, T.,GALAZKA, Z., GROCHOWIECKI, T., NAZAREWSCKI, S., SZMIDT, J.; Vascular access for hemodyalisis in patients with Cental vein Thrombosis; European Journal of Vascular and Endovascular Surgery, vol 442, issue 6, December 2011, pages 842-849 